\title{
Kernos
}

Revue internationale et pluridisciplinaire de religion grecque antique

5 | 1992

Varia

\section{Un dépôt de temple et le sanctuaire d'Artémis Amarysias en Eubée}

\section{E. Sapouna-Sakellaraki}

\section{(2) OpenEdition}

\section{Journals}

\section{Édition électronique}

URL : http://journals.openedition.org/kernos/1064

DOI : 10.4000/kernos.1064

ISSN : 2034-7871

\section{Éditeur}

Centre international d'étude de la religion grecque antique

\section{Édition imprimée}

Date de publication : 1 janvier 1992

ISSN : 0776-3824

\section{Référence électronique}

E. Sapouna-Sakellaraki, « Un dépôt de temple et le sanctuaire d'Artémis Amarysias en Eubée », Kernos [En ligne], 5 | 1992, mis en ligne le 19 avril 2011, consulté le 22 avril 2019. URL : http:// journals.openedition.org/kernos/1064; DOI : 10.4000/kernos.1064 
Kernos, 5 (1992), p. 235-263.

\section{UN DÉPÔT DE TEMPLE ET LE SANCTUAIRE D'ARTÉMIS AMARYSIA EN EUBÉE}

Il s'est écoulé exactement un siècle depuis que Wilamowitz, en 1891, et les archéologues américains qui firent des fouilles à Érétrie manifestèrent leur intérêt à explorer la région d'Amarynthos. Il s'agissait d'y découvrir le temple d'Artémis Amarysia. En 1885, Stavropoulos avait fouillé la colline de Palèohora où il supposait que devait se trouver le temple ${ }^{1}$. Kourouniotis entreprit également, entre 1897 et 1900 , de localiser le temple, mais l'opération fut infructueuse, en dépit de la découverte de divers indices à Anô et Katô Vathia, et dans des maisons de Paléohora, et d'inscriptions mentionnant la triade Apollon, Artémis et Léto ${ }^{2}$.

En 1902, Papavassiliou a mis au jour sur la colline des débris des époques classique et romaine, qui n'appartiennent cependant pas au temple et ne sont nullement en relation avec lui ${ }^{3}$.

J. Boardman traita lui aussi de ce thème, en faisant l'hypothèse de l'identité probable entre la colline et l'ancienne Amarynthos ${ }^{4}$.

Enfin, ceux qui eurent à s'occuper de l'histoire, de la topographie ou de l'épigraphie de la région reprirent la question de la localisation du temple de l'Artémis d'Amarynthos ${ }^{5}$.

Dans ce bref article, nous ne ferons pas référence à ce qui, entretemps, a été écrit sur le temple d'Artémis à Amarynthos, mais, en guise

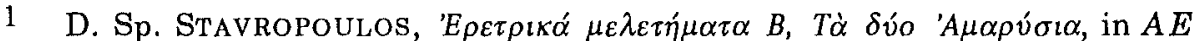
(1895), p. 158 sq. - Les Américains ont également montré un intérêt dans la découverte du sanctuaire lorsqu'ils firent des fouilles à Érétrie (AJA, 7 [1891], p. $142 ; 10$ [1895], p. 335).

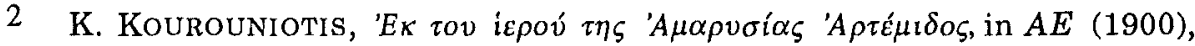
p. 6 sq.

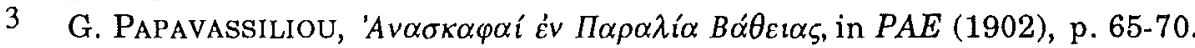
Cf. ci-dessous pour les découvertes les plus récentes de la colline, Paleohora ou Paleoklisia.

4 J. BOARDMAN, in ABSA, 52 (1957), p. 23-24.

5 C. Bursian, Topographie von Boeotien und Euboia, in Bericht der Sachs. Ges. d. Wiss. (1859), p. 131; E. ZIEBARTH, 'A $\mu \alpha \rho v \sigma o v$, in PAA, 10 (1935), p. $217 \mathrm{sq} . ;$

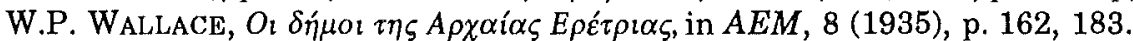
- Cf. la bibliographie dans H.J. GEHRKE, Eretria und sein Territorium, in Boreas, 11 (1988), p. 15 sq.; KNOEPFLER, Sur les traces de l'Artemisia d'Amarynthos près d'Erétrie, in CRAI (1988), p. 382 sq. 
de préliminaire, nous aborderons les principales inscriptions qui étayent la thèse de l'existence du temple dans la région. La mention la plus ancienne du nom apparait dans des tablettes en Linéaire B trouvées à Thèbes ${ }^{6}$.

Chez les écrivains de l'Antiquité, la référence à Amarynthos est essentiellement en rapport avec le culte d'Artémis : Pausanias (I, 31, 5) le rapproche des fêtes du dème d"A $A \mu$ ovías (Maroussi), de même que Strabon (X, 1, 10 [C448]), Ptolémée (III, 15, 24), Pindare (Ol., XIII, 159), Tite-Live (XXXV, 38), Élien (Des animaux, XII, 34), l'Anthologie grecque, I, 156. En outre, de nombreuses inscriptions apportent un témoignage sur le culte ou la fête des Amarynthies. La plus importante d'entre elles a été découverte à Aulonari et date de la fin du Ve siècle av. J.-C. ou du début du siècle suivant ${ }^{7}$.

Parmi les voyageurs plus récents, Vizenzo Mario Coronnelli dans l'Isolario (fin XVIIe siècle) rapporte que, dans la plaine d'Amarynthos, se trouvait un temple majestueux consacré à Artémis, soutenu par 80 colonnes (!), et que des fêtes (ou des mystères) y avaient lieu. En 1851, J. Girard rapporte que, du Kotylée, il pouvait distinguer le temple d'Artémis Amarysia ${ }^{8}$. Le renseignement est bien entendu inexact puisque, quarante ans plus tard, ni Wilamowitz, ni les archéologues américains, ni Stavropoulos ou Kourouniotis ne réussirent à le localiser, même si Bursian mentionne un "wohlerhaltenes Stück einer Umfassungsmauer" et Lolling un "große Anzahl antiken Quadern und Mauerzüge» ${ }^{9}$. Quelques ruines auraient donc encore été en place.

L'Artémision d'Amarynthos semble avoir été un des plus importants sanctuaires de la divinité, tant dans l'île d'Eubée elle-même - où se trouvait près d'Istiaia ${ }^{10}$ un autre Artémision connu, dont provient le petit "Jockey" du Musée National d'Athènes - que parmi les sanctuaires des rivages attique et béotien qui lui font face, tant celui d'Aulis que de Brauron.

D'après les inscriptions, le culte d'Artémis était, à l'époque, aussi important que celui d'Apollon. Les cérémonies en l'honneur d'Artémis

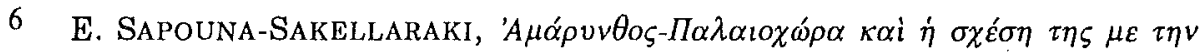

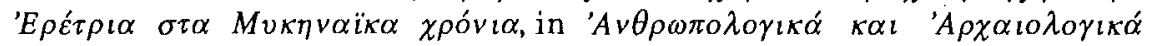
$\chi \rho \circ$ เкх́, 1 (1986), p. 67 sq.

$7 \quad A E(1902)$, p. 99.

8 J. Girard, Mémoire sur l'Eubée, in Archives des missions scientifiques et littéraires, 2 (1851), p. $636 \mathrm{sq}$.

9 GeHRKe, art. cit., p. 26, n. 61.

10 LOLLING, in $\operatorname{MDAI}(A), 8$ (1883), p. 7, 23, 200-210. 
d'Amarynthos avaient lieu entre le mois Anthestérion et Artémisios, et comprenaient des concours, des joutes musicales ${ }^{11}$, des sacrifices, des danses - dont la plus importante était la pyrrhique qui se déroulait en même temps que les Dionysies, des marches militaires dionysiaques, etc. ${ }^{12}$ Ces fêtes se déroulaient pour l'Eubée entière et nous savons qu'à l'époque macédonienne, Carystos y prenait également part ${ }^{13}$. Le sanctuaire de l'Artémis d'Amarynthos était si important que son trésor a, semble-t-il, contribué aux ressources d'Érétrie elle-même.

D'après les inscriptions, Artémis était adorée en Eubée sous les épithètes d'Ilithye ${ }^{14}$ ou d'Olympia ${ }^{15}$. Cette dernière marquait peut-être un rapprochement avec l'Olympe situé à proximité.

L'auteur de cet article s'est occupée de la question de l'emplacement du temple et, depuis 1983 déjà, ont été regroupées des cartes archéologiques indiquant les principales découvertes in situ lors de fouilles plus anciennes. C'était là un moyen de circonscrire, autant que faire se peut, l'emplacement le plus probable où devait s'élever le temple, conjointement avec l'inscription d'Aulonari (I.G., XII, 9, 189) qui le détermine

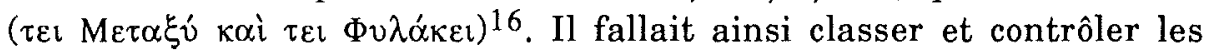
importantes découvertes de la fin du siècle dernier afin de savoir si le lieu des trouvailles correspondait bien à leur emplacement antique.

L'investigation commença par la colline de Palihoria ou Paleohoria ou Gérani (la section occidentale de la colline a parfois été appelée, dans les publications, "Vlahohoria»: I.G., XII, 9, 140). On y a trouvé des inscriptions portant les noms d'Apollon, de Léto et d'Artémis, comme la base de Phanokles (I.G., XII, 9, 140) trouvée en $1891^{17}$ sur le flanc occidental de la colline, à l'emplacement Blahohoria, et l'inscription mentionnant Léto, Artémis, Apollon (I.G., XII, 9, 143), découverte par Kourouniotis sur l'autel de l'Église de la Métamorphose du Sauveur ${ }^{18}$,

$11 A E$ (1902), p. 141.

$12 E \pi \imath \gamma \rho \alpha \varphi \eta^{\prime} A v \lambda \omega v \alpha \rho$ iov, in $A E$ (1902), p. 99.

13 Titus, LIV, 35, 38.

$14 A E$ (1902), p. 41.

$15 A E$ (1892), p. 141; I.G., XII, 9, 260.

16 On ne traite pas ici du problème, maintes fois étudié, de la distance entre Amarynthos et Érétrie d'après Strabon. On se ralliera au point de vue, vraisemblable, de D. KNOEPFLER, art. cit., p. 421, qui évoque une confusion entre les lettres $Z$ et $\Xi^{\prime}$, ce qui fait 60 stades et non pas 7. - Dans l'Hymne $\grave{a}$ Artémis de Callimaque (III, 188), le culte de la déesse a lieu dans $\lambda \mu \mu^{\prime} v \varepsilon \varsigma \gamma \varepsilon$ $\mu \dot{\varepsilon} v$ Eúpíroio.

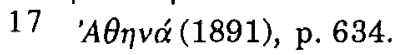

18 Kourouniotis, in $A E$ (1899), p. 141 sq. 
de même qu'un chapiteau. Othon Mihaïl y aurait également recueilli, en 1898, un poids en plomb portant sur une face un anthemia et sur l'autre l'inscription "Artémis»19.

Ces références à Artémis, de même que d'autres inscriptions votives, confirmèrent les chercheurs évoqués ci-dessus dans leur hypothèse que le temple d'Artémis devait se trouver au sommet de cette colline.

À l'occasion de l'étude sur l'Amarynthos préhistorique effectuée l'année dernière ${ }^{20}$ et dans le cadre d'une étude plus générale de la topographie d'Amarynthos (sch. 2), on a constaté, lors des tranchées effectuées en différents points de la colline, la présence de débris allant de la période classique à l'époque romaine, outre les ruines préhistoriques. Les périodes protogéométrique et géométrique ne sont donc pas représentées sur la colline. Les mêmes constatations ressortent des recherches effectuées au sud-est, à l'emplacement de Gyros. Cependant, en aucun point de la colline, on 'n'a pu trouver les traces d'un quelconque édifice ressemblant à un temple.

De surcroît, la colline ne correspond guère aux indices connus pour l'emplacement du sanctuaire, censé se trouver près de cours d'eau et de

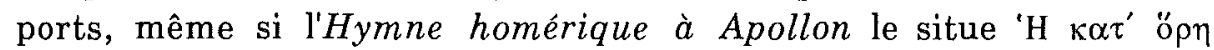
$\sigma \kappa \imath$ $\varepsilon \sigma \sigma \alpha$. De plus, les cérémonies décrites dans l'inscription d'Aulonari (I.G., XIII, 9, 187) demanderaient un espace plus étendu. Dès lors, si l'on peut supposer qu'un petit témenos se trouvait sur la colline, le sanctuaire principal devait se trouver quelque part dans la plaine.

Des inscriptions et d'autres éléments relatifs au culte d'Artémis n'ont pas été trouvés seulement sur la colline, mais dispersés sur une large étendue et même à grande distance, comme à Aulonari. Ainsi, le célèbre bas-relief votif du Musée National d'Athènes, reprenant la triade Apollon, Léto, Artémis et datant du IVe siècle av. J.-C., a été mis au jour en 1899 par Kourouniotis dans le village de Kato Vathia (aujourd'hui Amarynthos) sur le terrain de K. Barbouti, où s'élève à l'heure actuelle un édifice des télécommunications ${ }^{21}$. Il a donc été

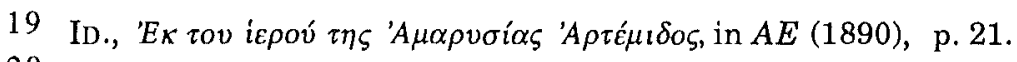

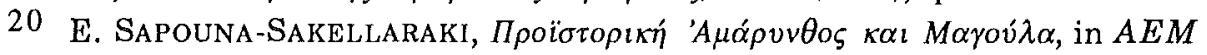
(1990), sous presse, où il est fait référence à tous les points de vue développés à propos de ce site préhistorique important, comme, par exemple, et entre autres, à l'investigation surperficielle des Anglais, cf. L. SACKETT, et alii, in ABSA, 61 (1966), p. 64 sq.

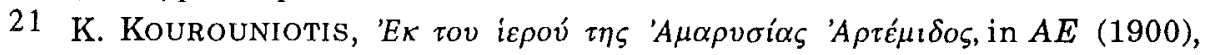
p. 5 sq., pl. 21. 
trouvé assez loin de la colline de Paléohoria (ou Gérani), avec d'autres matériaux de construction anciens.

L'omphalos a été découvert sur l'emplacement de Aghia Paraskevi ${ }^{22}$, qui ne peut être identifié avec l'église qui se trouve à Abélones, à $1000 \mathrm{~m}$ environ de la muraille orientale d'Érétrie, parce que, comme les dernières fouilles (1985) l'ont montré, on a trouvé, sous les ruines d'une église byzantine, des tombes de l'époque hellénistique, des stèles funéraires.

Par conséquent, l'emplacement de Aghia Paraskevi doit avoir un rapport avec une petite église qui se trouvait au nord-ouest de la colline de Gérani (Paleohora). Le rapport entre la triade et l'omphalos à Eubée est attesté par la stèle de Khairéphanès (M.Er. 1175).

Des inscriptions relatives à Apollon et à Artémis ont été découvertes dans deux églises assez éloignées de la colline, à Ano Vathia :

1. À Aghios Nikolaos, on a trouvé, avec des tambours de colonnes, des chapiteaux et des stèles funéraires, une base provenant, semble-t-il, de la région de Marmara, près de Sarandapotamos (l'ancien Erassinos), sur la côte de Vathia et qui est une dédicace d'Oropiadès à Artémis, Apollon, Léto (I.G., XII, 9, 142). La région de Marmara est particulièrement intéressante comme lieu de découverte.

2. Dans l'église de la Vierge, sur la route qui monte à Ano Vathia, se trouve, sur une base datant du Ier siècle av. J.-C., une inscription dédiée

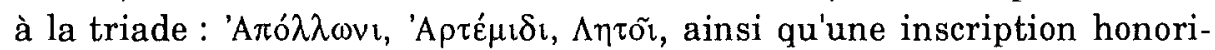
fique du Ier siècle av. J.-C. dans un mur extérieur de l'abside; il s'agit d'un décret du dème d'Érétrie à Héraclitos Démétrios, et consacré à Artémis, Apollon et Léto. S'y trouvent aussi de nombreux fragments architecturaux.

Dans l'église Aghios Ioannis, dont nous ne savons pas à quel point elle appartient à Kato Vathia, on a trouvé une inscription votive APTEMI... (I.G., XII, 9, 153).

Par conséquent, les inscriptions se rapportant à Artémis ont été trouvées dans la région située entre l'actuelle église des saints Anargyres, la colline de Gérani, Panayitsa de Ano Vathia et Chireon, qui s'identifie avec l'actuel port de Kato Vathia, d'où provient le basrelief du Musée National. Cependant, il semble qu'aucun de ces indices n'ait été trouvé in situ, mais en des lieux inattendus, avec des stèles funéraires et d'autres éléments.

Les seuls éléments qui pourraient permettre d'éclairer la question de la localisation sont un espace souterrain à l'emplacement de

22 ID., in $A E(1900)$, p. 19. 
Sarandapotamos ou Potamos, qui constitue peut-être une source sacrée, et un édifize carré de $6,85 \times 6,5 \mathrm{~m}$ au lieu-dit Paléos Volos ou Manides, où Papavessiliou avait effectué des fouilles ${ }^{23}$. Dans cette région, ainsi que dans celle située entre la petite église de Aghia Kyriaki, les saints Anagyres et la nouvelle fabrique de glaces, nous avons remarqué d'énormes pierres ayant appartenu à un ou plusieurs édifices, démolis par la rage de construire qui sévit au cours des dernières décennies.

Donc, sur la carte indiquant la dispersion des inscriptions et des débris, la région située autour d'Aghia Kyriaki, près de la rivière et du port, a été déterminée comme l'emplacement le plus significatif parmi ceux qui pourraient convenir au temple de l'Artémis d'Amarynthos, d'après les matériaux dispersés tout autour. Une découverte due au hasard (fouilles clandestines) confirma ce qui avait été pressenti par la recherche topographique.

En 1987, dans le champ de N. Mihaïl, a été révélée l'existence d'un trafic d'antiquités, qui mena aux fouilles et à la découverte d'un grand dépôt. Le nom du propriétaire rappelle celui du personnage qui remit à Kourouniotis le poids en plomb portant l'inscription «Artémis» sur l'une de ses faces ${ }^{24}$.

Les fouilles eurent lieu en trois phases suivies sur le terrain Mihaïl et par des coupes qui permirent la découverte d'un dépôt de $16 \times 23 \mathrm{~m}$ (368 $\mathrm{m}^{2}$ ). Elles devront s'étendre davantage vers l'est, où se trouve la propriété de G. Théophanis. Le terrain de Mihaill se trouve au sud d'un chemin de terre, à l'ouest du terrain de Théophanis, au sud de la propriété de Hatzis. Le champ n'a jamais été construit et consiste en une petite olivette.

Dans la tranchée A-T, on n'a pas trouvé de traces de bâtiments, sauf une construction dans la tranchée $\Theta$. Les objets ont été trouvés dans une couche à $0,60 \mathrm{~m}$ sous la surface jusqu'à une profondeur de $1,40 \mathrm{~m}$. Dans un cas, la tranchée $P$, elle descend jusqu'à $1,80 \mathrm{~m}$, là où apparaît une couche de sable marin avec des cailloux ronds.

Les découvertes, datées du début de la période archaïque jusqu'aux premières années de l'époque byzantine, ont été faites sans une claire description des couches, ce qui renforce l'idée qu'il s'agit d'un dépôt. On peut ainsi expliquer que les matériaux ont bougé et que des apports

23 Th. MoIros, in $A E$ (1902), p. 152.

24 K. Kourouniotis, in $A E$ (1900), p. 21. - Le champ est vraisemblablement le lot 16 qui appartient aujourd'hui à Pan. Th. Mihail. Puisque le poids n'a pas été trouvé par le fouilleur mais lui a été remis, il est possible qu'il ait été découvert ailleurs et donné comme provenant d'un autre endroit, pratique connue de "l'attribution de provenance», quand il s'agit de lieux célèbres. 
continuels ont été effectués. Il ne s'agissait vraisemblablement pas d'un atelier de fabrication de terres cuites, puisqu'on n'a pas trouvé de matrices, pas plus que d'autres matériaux qui autorisent une telle interprétation. Au contraire, tout ce qui a été découvert semble appartenir à la sphère du sacré.

Sur le terrain Mihaïl, on a trouvé de nombreux objets en argile, en cuivre, en marbre, en plomb et en verre. Ce sont des statuettes en argile et des vases qui constituent la majeure partie des découvertes. Voici la liste des trouvailles:

\section{En métal}

- une lame en plomb qui peut avoir appartenu à un siège (trône); elle comporte une sorte de boulon et est décorée d'une résille ${ }^{25}$. De telles lames sont connues; on en a notamment trouvé dans le temple d'Artémis Orthia à Sparte;

- une lame de plomb circulaire qui rappelle un sceau porte une forme nue debout, probablement Apollon ${ }^{26}$;

- une lame de plomb en forme de lion.

Ces trois lames, avec le poids trouve̊ au flanc oriental de la colline d'Amarynthos et portant le nom d'Artémis ${ }^{27}$, relient les dêcouvertes du dépôt à des objets laconiens.

- trois fibules de type insulaire ${ }^{28}$ de la fin du VIIIe, début VIIe siècles av. J.-C., une fibule en or avec des points dorés aux extrémités ${ }^{29}$, ainsi que la spirale d'une épingle, constituant des objets d'usage personnel déposés dans la fosse sacrée avec une bague de cuivre, une autre en argent et un anneau de cuivre. Assurément, il s'agit d'un dépôt fait par des femmes, comme c'est également le cas à Brauron et dans le sanctuaire d'Artémis Brauronia sur l'Acropole.

\section{En pierre}

Un pilon en marbre blanc a été trouvé au centre de la tranchée (coupe 丹) ainsi que des fragments de couvercles de pyxides en marbre blanc

25 I. MetZger, Das Thesmophorion von Eretria, in Eretria, XII (1985), pl. 31, fig. 1610.

26 Archeological Reports (1986-1987), p. 21, fig. 28.

27 Cf. supra, n. 24.

28 Type IV B-C. E. SAPOUNA-SAKELLARAKI, Fibeln der griechischen Inseln, München, 1978, pl. 22, n 649, 23; 667, 30.

29 P. JACOBSTAHL, Greek Pins, Oxford, 1956, nº 318 : postérieur et pas exactement semblable. 
semblables à celles que l'on a trouvées dans le temple d'Artémis à Brauron ${ }^{30}$.

\section{En verre}

À part les quelques boules en verre découvertes dans le dépôt, on a aussi trouvé des vases entiers et des vases brisés :

a) une oenochoé à l'embouchure trifoliée en verre bleu avec une ouverture bordée de jaune; on trouve déjà ce type de vases à partir du VIIe siècle ${ }^{31}$, mais il y en a encore aux IVe et IIIe siècles av. J.-C. ${ }^{32}$

b) un fragment de vase en verre - de la même forme que ceux en albâtre - avec un décor de branche rappelant des modèles syro-palestiniens ${ }^{33}$. Il est daté du IVe-IIIe siècle ${ }^{34}$.

c) une petite amphore de couleur bleue avec des lignes jaunes en zigzag sur sa partie ventrue, de type phénicien ${ }^{35}$, datée entre le VIe et le IVe siècles av. J.-C. ${ }^{36}$

À Brauron, on a trouvé des objets semblables à a) et c).

\section{Pesons de fuseau-poids de tisserand}

On a retrouvé bon nombre de pesons de fuseau, tant du type bas, rappelant des modèles mycéniens, que haut, peints en noir ${ }^{37}$, ornés de bandes noires. Les poids de tissage sont du type pyramidal, souvent avec un sceau.

\section{Céramique}

La céramique est abondamment représentée et ne peut être traitée ici de manière exhaustive. Il faut cependant souligner que les vases les plus anciens remontent à la fin de la période géométrique et archaïque ancienne. Parmi ceux-ci, on note un nombre significatif d'aryballes protocorinthiens, ensuite de nombreux vases à figures noires, principalement des lécythes, assez blancs (photo 1), mais aussi un nombre de calices des «little-masters", avec des représentations de chars, des scènes bachiques, des scènes d'athlétisme et autres, de même que des cratères avec des représentations de chevaux, des anthemia et autres.

30 Ergon (1962), p. 32, fig. 41.

31 S. Moscati, The Phoenicians, Venezia, 1988, p. 478, 9.

32 Ibid., p. 477.

33 Ibid.

34 A. von SAldern, Glass von Antiken zum Jugendstil, Mainz, 1980, $\mathrm{n}^{\circ} 19$.

35 MosCATI, op. cit., p. 489.

36 Ibid., p. 479.

37 I. METZGER, op. cit., pl. 15, 250, 255. 
Du point de vue de la céramique à figures noires, il est significatif que l'on trouve deux surmoulages dont l'un est orné d'une scène de banquet (photo 2), l'autre de femmes, ce qui renvoie assurément à la période connue des surmoulages d'Érétrie ${ }^{38}$. Un fragment de la tête d'un nègre provient vraisemblablement d'un vase modelé.

La céramique à figures rouges, du Ve siècle av. J.-C., a également une grande importance : beaucoup de tessons qui devront être recollés sont d'une excellente qualité et comportent des thèmes riches. Une Victoire qui porte un thyrse est peut-être une Artémis ailée. Mentionnons encore un tesson à figures rouges du IVe siècle provenant d'un cratère représentant des Arimaspes et des griffons.

Enfin, de nombreux tessons datent de la période hellénistique, skyphos et petites coupes mégariennes brisées ou entières ${ }^{39}$. Des pots à sel (salt-cellars), hydries, à vernis noir ou décorées, petites coupes et vases en noir avec des reliefs, de petites amphores avec des anses haut placées sont les types de vases les plus courants.

Une catégorie bien représentée est faite de vases avec de petits dessins (sch. 4-5), caractérisés par la variété des formes en petites corbeilles, bowl (petites lances) avec, en relief, des rayures verticales, à base haute ou le plus souvent de niveau. Beaucoup d'entre eux sont de couleur bleue, etc. Il faut souligner que des vases de ce type ont été découverts dans le Thesmophorion d'Érétrie, ce qui prouve leur caractère cultuel ${ }^{40}$.

\section{Lampes}

Bon nombre d'entre elles ont été trouvées dans le dépôt d'Aghia Kyriaki; elles datent pour la plupart du Ve siècle av. J.-C.41 (photo 3), mais certaines sont postérieures à cette époque.

\section{Reliefs en argile}

a) gorgoneion en forme de plaque d'argile : cet objet rejoint directement la grande gorgone trouvée à Érétrie ${ }^{42}$. L'objet était bien entendu en rapport avec un ustensile;

\footnotetext{
38 J. BEAZLEY, $A R V^{2}, 1250,34$.

39 H. \& D. Thompson, The Hellenistic Pottery and Terracottas, Princeton, 1987, p. 381 , fig. 67.

40 METZGer, op. cit., pl. 15, 314.

41 R. Howland, The Athenian Agora, IV:The Greek Lamps and their Survivals, Princeton, 1958, pl. 34, type $20 \mathrm{c}$.

42 Eretria, site de la Grèce antique, in Histoire et archéologie, mai 1985, p. 68.
} 
b) relief avec une sirène aux ailes ouvertes comme une Victoire qui foule du pied une base en forme de faux avec spirale; le thème est principalement connu par des vases en cuivre ${ }^{43}$;

c) relief, plaque avec un pilier hermaïque et deux figures, probablement les Grâces ${ }^{44}$. Cependant, Hermès est souvent associé à Artémis et à Léto 45 (photo 4);

d) fragment de plaque en relief avec une tête portant une coiffure conique, comme celle de l'Artémis Bendis; derrière la tête, un relief représente un arbre, peut-être un palmier. Il s'agit peut-être d'une représentation d'Artémis Dendritis ${ }^{46}$. Un orifice de raccord apparait dans un angle qui subsiste.

De telles plaques en relief étaient peut-être rapportées à des meubles ${ }^{47}$. Beaucoup d'entre elles, datées du milieu du Ve siècle av. J.C., ont été trouvées à Mélos ${ }^{48}$, mais aussi à Locres ${ }^{49}$, à Tarente ${ }^{50}$, à Paestum ${ }^{51}$, avec une représentation d'Artémis du type Bendis. En Cyrénaïque, on a retrouvé des plaques en relief avec gorgoneion ${ }^{52}$.

Bustes (photos 5a-c)

Nombreux sont les bustes datés du début du Ve siècle av. J.-C., tant avant que juste après les Guerres Médiques. Le type le plus fréquent porte deux ou trois rangs de boucles en spirale sur le haut du front, séparés au milieu, et un voile ou un diadème simple ou orné de rosaces.

\section{Statuettes de femmes}

Peu d'entre elles appartiennent à des types antérieurs au VIe siècle av. J.-C. La plus représentative est la tête à la coiffure dite «Etagen Frisur» (photo 6), portant le polos et qui doit appartenir à la fin du VIIe

43 Archaeological Reports (1987-1988), fig. 52 (anse d'hydrie en cuivre postérieure à 350 av. J.-C.) et sirène sur anse : M. ANDRONIKOS, $\Phi I \Lambda I \Pi \Pi O \Sigma$, 'A $\theta \dot{\eta} v \alpha$ (1980), p. 142, fig. 72.

44 G. DonTAS, The Acropolis and its Museum, Athens, 1979, fig. 79.

45 L. KAHIL, art. Artemis, in LIMC, II (1984), n 1167, 1171a.

46 Ibid., $\mathrm{n}^{\circ} 740$.

47 R.A. Higgins, Catalogue of the Terracottas in the British Museum, I, London, $1969^{2}$, p. 7, n. 6.

48 HigGINS, op. cit., p. 166-167.

49 Ibid., p. 330, n 1215.

50 Ibid, p. $361, \mathrm{n}^{\circ} 1328$.

51 Ibid., p. 377, n' 1402.

52 Ibid., p. 392, nº 1487-1488. 
siècle, parallèlement à des statuettes de ce type retrouvées en Crète ${ }^{53}$ et à Rhodes ${ }^{54}$. Un buste d'homme avec des boucles tombant sur les épaules ainsi qu'une figurine articulée appartiennent aussi à cette période.

La plupart des figurines de la fin du VIe ou du début du Ve siècle représentent des femmes assises, portant le polos 55 , souvent sur des trônes dont les accoudoirs se terminent en anthemia ${ }^{56}$. Le dessin est de couleur rouge sur fond blanc.

Plusieurs de ces femmes assises sur un trône tiennent un petit lion ${ }^{57}$, un cerf ${ }^{58}$ (photos $7-8$ ), une fleur ou un petit enfant ${ }^{59}$. Ce type de la Kourotrophos s'identifie souvent à Artémis qui, outre ses autres attributions, est la protectrice de la famille. C'est pourquoi il lui arrive d'être identifiée à Ilithye et, au cours de la période hellénistique, l'Artémis $\Lambda$ o $\varepsilon i \alpha$ préside aux accouchements.

À Athènes, la partie du corps dit «triangle de Vénus» (pubis) était consacré à la déesse portant l'épithète de Kallistè.

Le type de l'Artémis debout avec un animal quelconque, habituellement un cerf ${ }^{60}$ à côté d'elle, mais aussi un chien 61 , en particulier le type d'Artémis Bendis (photo 9a), est connu au Ve siècle, ainsi qu'au IVe siècle. Un autre type apparaît, celui de l'Artémis debout qui, dans la main droite, tient une fleur qu'elle porte à son sein. Les statuettes d'Artémis assise et debout appartiennent aussi au IVe siècle; elle est représentée portant une tunique ionienne, manteau et diploidion retenu par des lanières croisées, du type connu par un cratère à figures rouges de Naples ${ }^{62}$. Dans certains cas, aux IVe et IIIe siècles, elle porte un collier, comme c'est le cas à Chypre au Ve siècle av. J.-C. ${ }^{63}$

Outre celles d'Artémis, de nombreuses statuettes représentent Apollon portant tunique et manteau, et, dans la main gauche, une

53 S. BESques-MollaRd, Catalogue raisonné des figurines et relief en terre cuite, Paris, 1954-1986, pl. XXI, B165, B167, de la fin du VIIe siècle av. J.-C.

54 HigGins, op. cit., pl. 6, 38 et 5, 29.

55 Ibid., p. 820, pl. 113, provenant de Béotie, milieu du Ve siècle av. J.-C., et de Rhodes (BESqUES-MoLLARD, op. cit., I [1954], pl. XXVII, B220).

56 HigGINs, op. cit., p. 889, pl. 129.

57 Cf. le type Artémis in LIMC, II (1984), pl. 498, n 663b.

58 Ibid., $\mathrm{n}^{\circ} 665$.

59 Ibid, pl. 504, n० 721.

60 Ibid., pl. 497.

61 HigGINS, op. cit., p. 196, n 73, pl. 96.

62 LIMC, II (1984), pl. 541, n 1179.

63 Ibid, pl. $496, \mathrm{n}^{\circ} 639$. 
cithare. Des fragments de mains portant une grenade ou une phiale devraient être attribués à Artémis ou à Léto, d'après le bas-relief de Larissa conservé au Musée National d'Athènes ${ }^{64}$. Souvent Léto et Artémis sont l'objet d'un rapprochement et partagent des attributs avec Déméter et Perséphone.

On a découvert un ensemble important de statuettes "Tanagra» (photo 9b), assises ou debout, avec sur la tête un manteau qui cache le visage à la manière d'un masque. Des têtes leur appartenant se distinguent par des coiffures compliquées, des renflements, des torsades, des diadèmes en métal - les dites "Melonen Frisuren" caractéristiques des offrandes des IVe et IIIe siècles av. J.-C. Des têtes avec des polos cylindriques désignent Artémis et Déméter. Les robes des danseuses épousent souvent le mouvement ondoyant des sculptures du haut IVe siècle av. J.-C. ${ }^{65}$

Peu d'autres divinités sont représentées. Certaines statuettes figurent Pan avec la phorminx ${ }^{66}$, assis ou debout, portant un fardeau quelconque sur l'épaule. On trouve aussi des représentations, vraisemblablement d'Aphrodite, d'un type connu en Béotie ${ }^{67}$ au IVe siècle av. J.C., ou de Dionysos - une tête du Ier siècle av. J.-C. ${ }^{68}$ - dont le culte est associé à celui d'Artémis dans les inscriptions en relation avec Amarynthos, comme on l'a vu précédemment. On trouve encore Apollon avec la lyre ou la cithare (photo 10).

Une multitude de statuettes, cependant, représentent des enfants, filles et garçons. Pour ce qui est des filles, on connait les "ourses» de Brauron et les rites dédiés à Artémis par ces petites filles. Les nombreux petits garçons pourraient trouver un parallèle en Élide où Artémis porte l'épithète de "Philomeirax" 69 parce qu'on l'honore près du gymnase. Peut-être une relation semblable se produit-elle ici. De surcroît, on trouve parmi les statuettes les dits "Crouching Boys", des enfants consacrés dans les sanctuaires. Une des raisons de l'existence de ces jeunes garçons se trouverait ainsi expliquée.

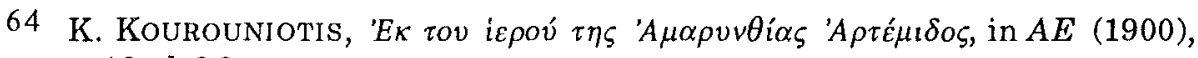
p. 16, pl. 2.2 .

65 HigGINs, op. cit., pl. 93, n 715.

66 Ibid., p. 317, n 169, pl. 159.

67 Ibid., pl. $123, \mathrm{n}^{\circ} 862$.

68 BESQUES-MOLLARD, II (1963), pl. 96.

69 PAUS., VI, 23, 8.
} 
Les statuettes d'enfants appartiennent à plusieurs types. La multitude de ces types et leurs variantes nous contraignent à nous limiter ici au recensement des plus importants d'entre eux (photo 11) :

1) type de fillette ou de garçonnet debout qui joue de la flûte; il correspond à une modèle d'Érétrie, de Cyrénaïque et de Sicile (IVe siècle av. J.-C. $)^{70}$;

2) type de jeunes filles ou de femmes (IVe siècle av. J.-C.) portant un kanistron; il est connu en Attique ${ }^{71}$ pour les cérémonies de mariage; le kanistron contient, selon Higgins, des offrandes pour Artémis. Une figure féminine avec kanistron (photo 12) est représentée sur le relief de Brauron avec la triade Léto, Apollon, Artémis recevant un sacrifice de taureau; l'œuvre date du IVe siècle av. J.-C. ${ }^{72}$;

3) fillettes avec manteau, portant un chapeau conique, la tholia et tenant une couronne (IIIe siècle av. J.-C.) ${ }^{73}$ (photo 13);

4) fillettes portant un tympanon sur l'épaule gauche, en tunique et manteau (IIIe siècle av. J.-C.) ${ }^{74}$ (photo 14);

5) fillettes en manteau tenant seulement un tambourin rond du type du IVe siècle av. J.-C. correspondant tant à celui de Tarente qu'à celui d'Érétrie ${ }^{75}$;

6) fillettes en tunique et manteau, assises ou debout, portant une grappe de raisin ${ }^{76}$. Besques-Mollard attribue ce type à des divinités. Des figurines d'hommes et de garçonnets portent aussi des grappes de raisin;

7) fillettes en tunique et manteau, portant un petit sac à la main droite; ce thème correspond tant à la Béotie (début du IIIe siècle) ${ }^{77}$ qu'à Érétrie ${ }^{78}$;

8) hommes ou garçons, nus ou avec un manteau, portant un petit sac (comme au $\mathrm{n}^{\circ} 7$ ) (photo 11);

9) hommes ou garçons, debout, portant une grappe de raisin (comme au n ${ }^{\circ}$ ) (photo 15);

10) hommes ou enfants nus s'appuyant à une colonne;

70 HigGINS, op. cit., p. 319, n 1179, pl. 161; METZGER, op. cit., pl. 16, 20, 21.

71 Ibid., p. 195, n 729, pl. 95.

72 LIMC, II (1984), pl. 536, $\mathrm{n}^{\circ} 1127$.

73 Besques-MollaRd, III, 1 (1972), pl. 18, D80.

74 Ibid., $\mathrm{n}^{\circ} \mathrm{D} 368$.

75 HigGINS, op. cit., n 1336, pl. 186; METZGER, op. cit., pl. 16, 2.

76 Besques-Mollard, IV, 1 (1986), pl. 21.

77 Ibid., III, 1 (1972), p. 35, pl. 431, D193.

78 METZGER, op. cit., pl. 116, $\mathrm{n}^{\circ} 36$. 
11) hommes ou enfants ou danseuses, assis sur un rocher;

12) enfants tenant une couronne ou la portant autour du cou, ou tenant un collier de fleurs (photo 13); ces couronnes renvoient aux

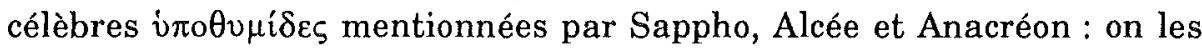
portait afin de combattre l'odeur du vin avec celle des fleurs. Athénée,

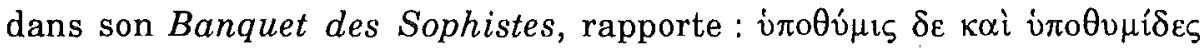

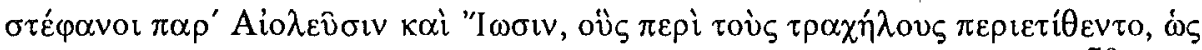

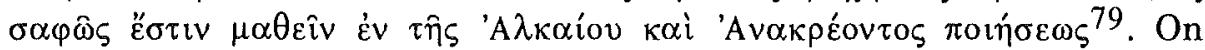
portait aussi des guirlandes en l'honneur d'Ilithye qui, comme nous le savons, est proche d'Artémis;

13) enfant assis écrivant sur un diptyque, thème qui se rapporte à la Béotie (IIIe siècle av. J.-C.) ${ }^{80}$ (photo 16);

14) enfants debout, dont le corps est dissimulé par un manteau jusqu'au genou et portant une couronne ${ }^{81}$; ce type de Béotie date du Ve siècle av. J.-C.

Il y a bon nombre de couples : ces figurines appartiennent au cycle de Dionysos ${ }^{82}$ et sont identifiées à Éros et à Aphrodite (IVe siècle) ${ }^{83}$ ou encore à la Kourotrophos avec un petit enfant debout ${ }^{84}$.

Parmi les têtes conservées, dont les coiffures sont variées, bon nombre portent un chapeau conique. Ce type de chapeau est connu pour les Amazones ou encore les danseuses à l'oklasma ${ }^{85}$. Cependant, il doit s'agir de l'Artémis Bendis. La déesse thrace Bendis arriva à Athènes au Ve siècle av. J.-C. Hérodote donne le nom d'Artémis à cette divinité guerrière de Thrace ${ }^{86}$. À partir de 431 av. J.-C., des fêtes en l'honneur d'Artémis Bendis ont lieu à Athènes, avec cortèges, offrandes sacrificielles, processions aux flambeaux et banquets. À partir de 332 av. J.-C., pour les Athéniens, Bendis n'était plus qu'Artémis.

On a trouvé beaucoup de sortes d'animaux et d'oiseaux dans le dépôt, soit isolés, soit en relation avec des figures humaines, surtout des enfants. Parmi les animaux les plus courants, après le cerf et le lion, on trouve le taureau, animal qui se rattache à Artémis, l'agneau, le renard, le coq, la perdrix, le cheval, la colombe - avec plusieurs

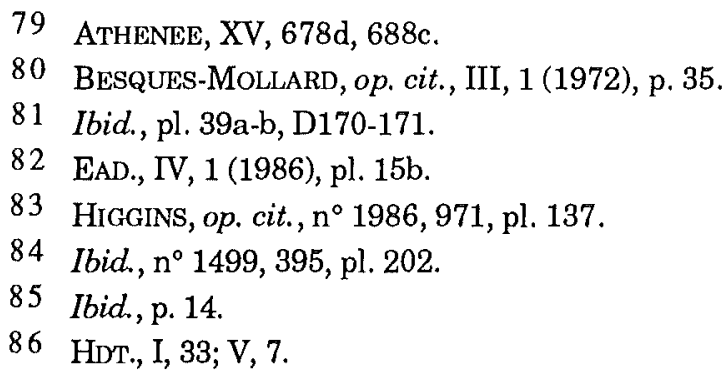


variantes -, la cigale, l'abeille et la tortue, se rapportant à Artémis et à Apollon. Ensuite viennent le porc, le bélier, le chien, ainsi que le serpent, associé aux divinités chtoniennes, particulièrement à Hécate et à Zeus Meilichios, mais également en relation avec le Python d'Apollon, tandis que le cheval est associé à Artémis Orthia. Outre ces animaux, des figurines représentant des êtres mythiques, comme les sirènes, ont été déposées à cet endroit.

La combinaison des êtres humains et des animaux est très variée, surtout en ce qui concerne les enfants: l'enfant au chien, l'enfant au chapeau conique sur un coq, analogue à un type béotien ${ }^{87}$ (IIIe siècle av. J.-C.), enfant assis sur un oiseau ${ }^{88}$ (fin du Ve siècle) rappelant les "Crouching Boys" (enfants accroupis).

Les coquillages marins sont moins nombreux. Par contre, il y a beaucoup de piliers hermaïques simples ou combinés, avec un enfant au chapeau conique. Il y a encore des colonnes isolées. Peu d'Éros des IVe et IIIe siècles av. J.-C. sont représentés dans le dépôt.

Enfin, on trouve de nombreuses statuettes d'acteurs avec des masques provenant de la Nouvelle Comédie (photo 12 en haut et en bas, à droite) qui commence en 330 av. J.-C. Le type le plus courant est celui du Paposilène avec une corbeille (IVe siècle av. J.-C.) ${ }^{89}$, du Paposilène avec Dionysos, le type du Paposilène assis, avec haut pilos, de l'esclave, de la nourrice ventrue accompagnée d'un enfant, etc.

Il ressort de cette description succincte des fouilles effectuées dans le champ Mihaïl qu'il s'agissait d'un temple riche, très ancien, consacré à une divinité féminine en relation avec la nature et les animaux (Potnia thêrôn), avec bon nombre d'éléments ayant trait à une divinité chtonienne (Hécate), comme l'attestent le gorgoneion et la grenade.

La déesse est associée à d'autres divinités, comme Apollon, Hermès, Dionysos, Pan; elle est la protectrice des enfants (Ilithye) et, aux VIe-Ve siècles, elle est représentée comme Cybèle. Elle a des attributs (cithare, flûte, tympanon, crotales) qui l'associent à la musique et à la danse (Artémis Hymneia) ainsi qu'au théâtre.

Ce dépôt doit avoir été en usage pendant longtemps. Un temple fonctionnait certainement avant les Guerres Médiques, florissait après celles-ci; les IVe et IIIe siècles constituent également une période de prospérité. Les découvertes du IIe et du Ier siècle sont en nombre légère-

87 Besques-Mollard, op. cit., III, 1 (1972), pl. 83a, p. 35.

88 HigGINS, op. cit., p. 222, n 834 , pl. 114.

89 Besques-Mollard, op. cit., IV, 1 (1986), pl. 16. 
ment inférieur et il semble que, au Ier siècle, le temple n'était plus en service.

Les éléments iconographiques présentés par les statuettes coïncident avec ceux qu'évoque l'inscription d'Alivéri, dans laquelle il est question de défilés de cavaliers, de musique, de danse, ainsi que de représentations théâtrales. C'est ainsi que, avec la céramique exceptionnellement importante, conjointement aux autres découvertes, le dépôt peut être associé au culte d'Artémis et, de ce fait, à l'Artémis d'Amarynthos.

Les fragments de constructions, la topographie, les témoignages que constituent les inscriptions, ainsi que les autres découvertes faites alentour viennent enfin répondre à la question posée depuis un siècle au moins sur la localisation de ce sanctuaire qui doit se trouver dans les environs.

Éphorie des Antiquités préhistoriques

E. SAPOUNA-SAKELLARAKI Chalcis-Eubée
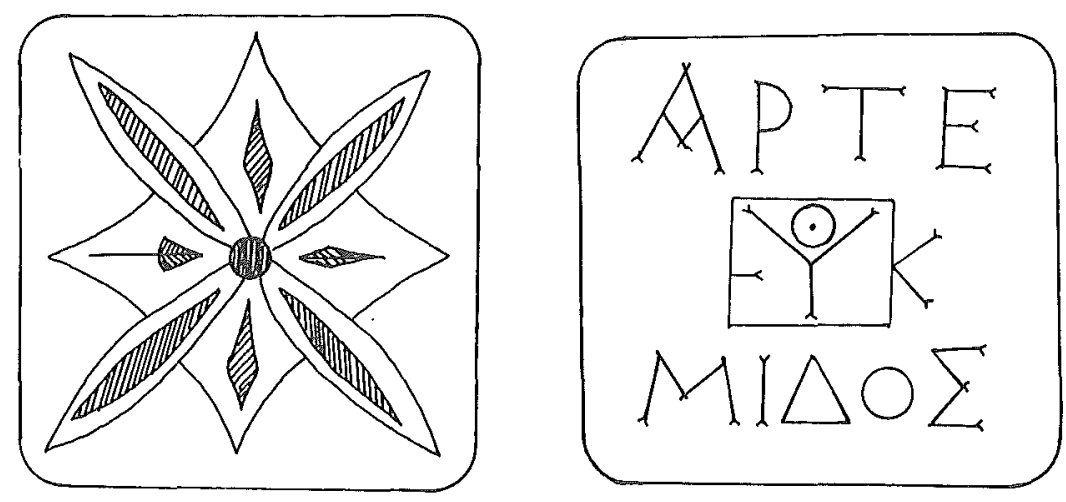

Dessin 1 

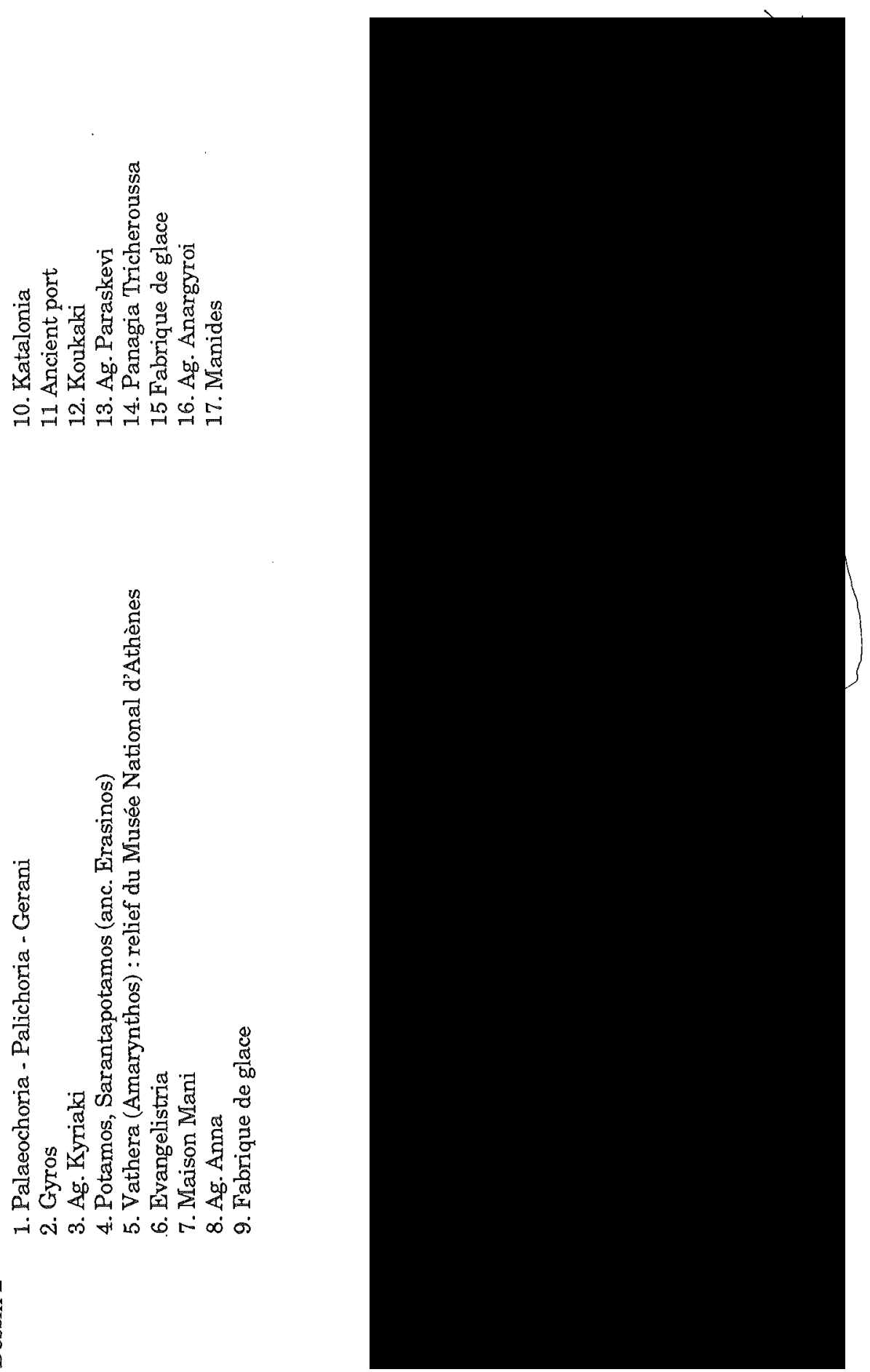

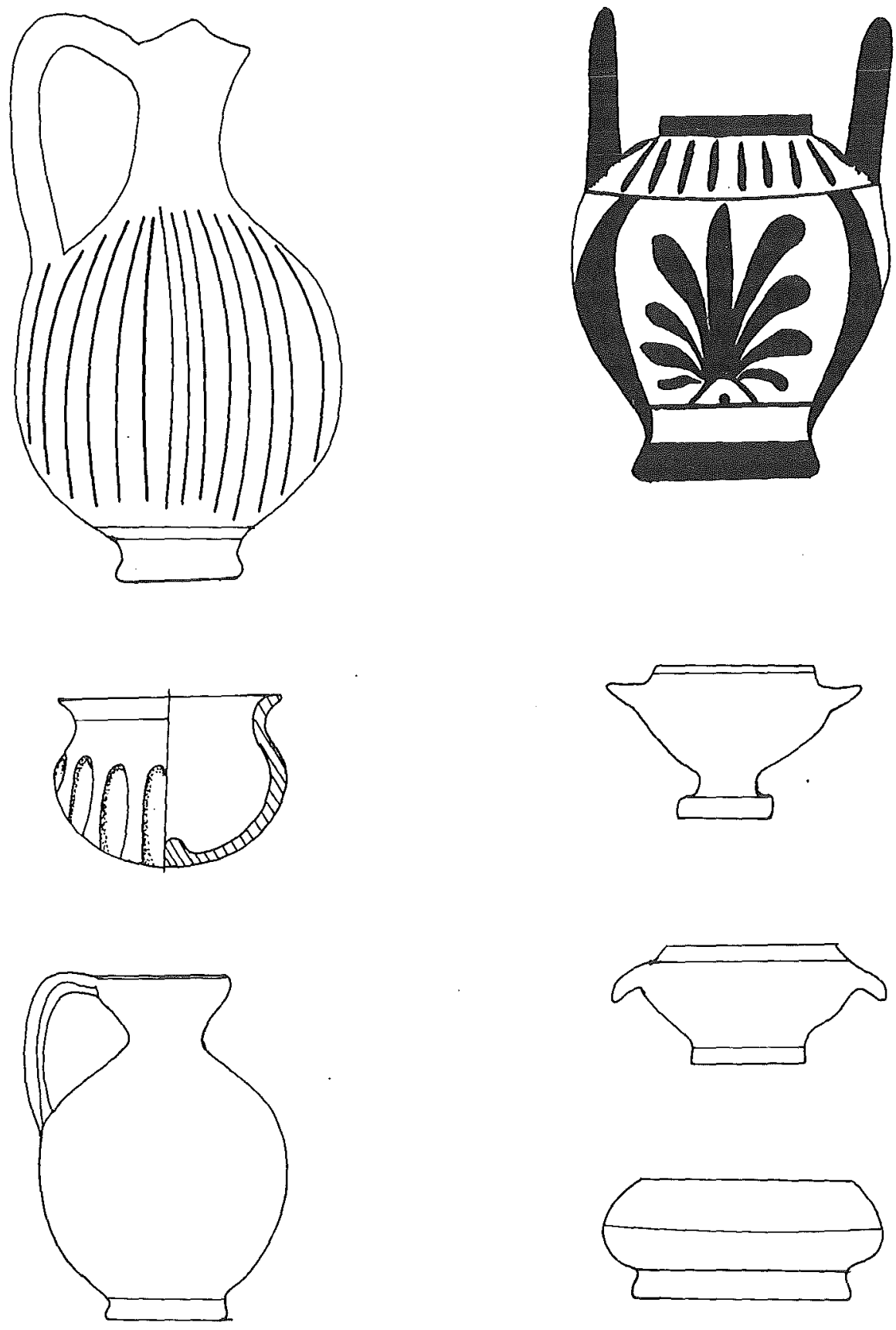

Dessin 3 

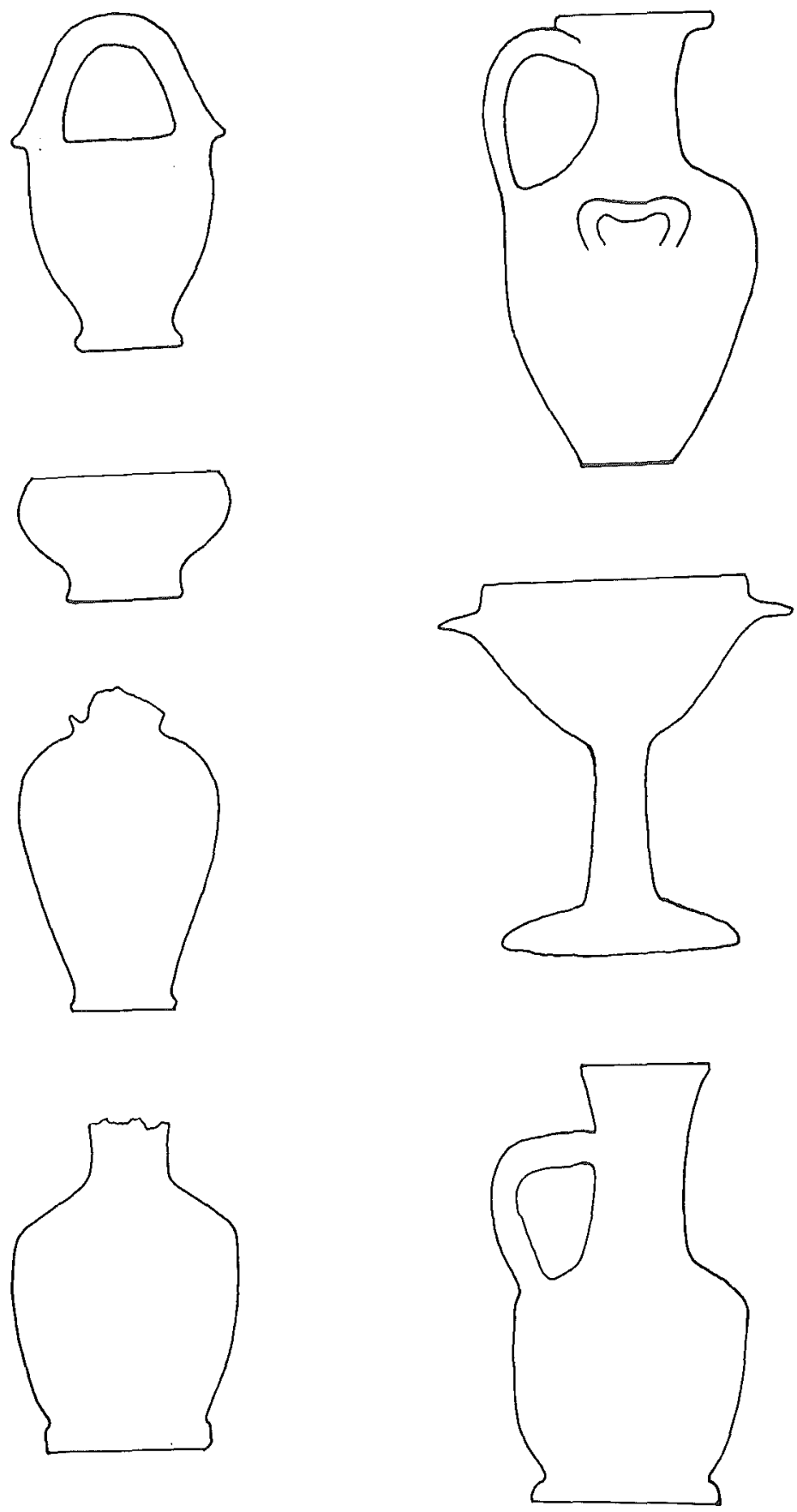

Dessin 4 

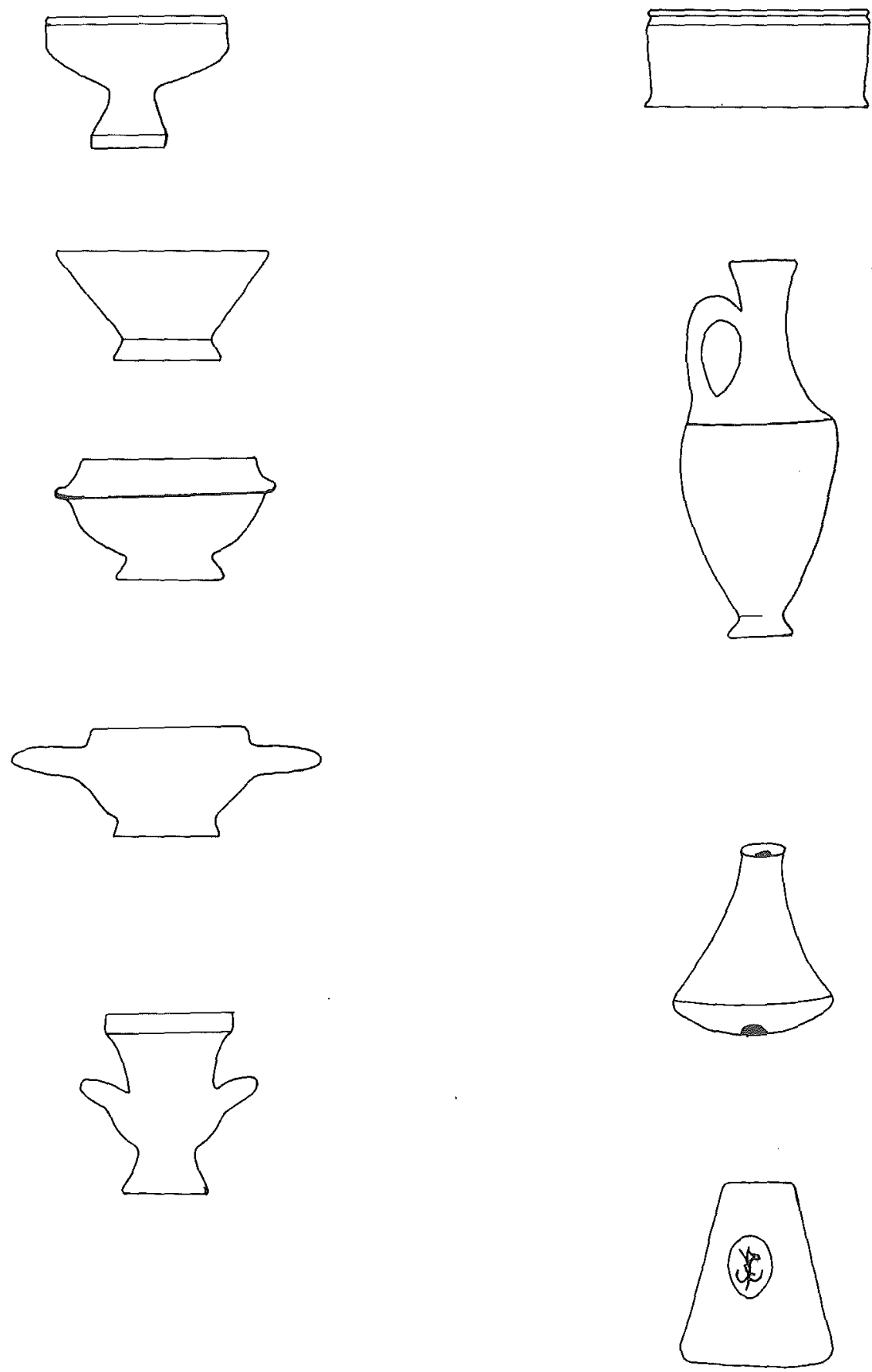

Dessin 5 


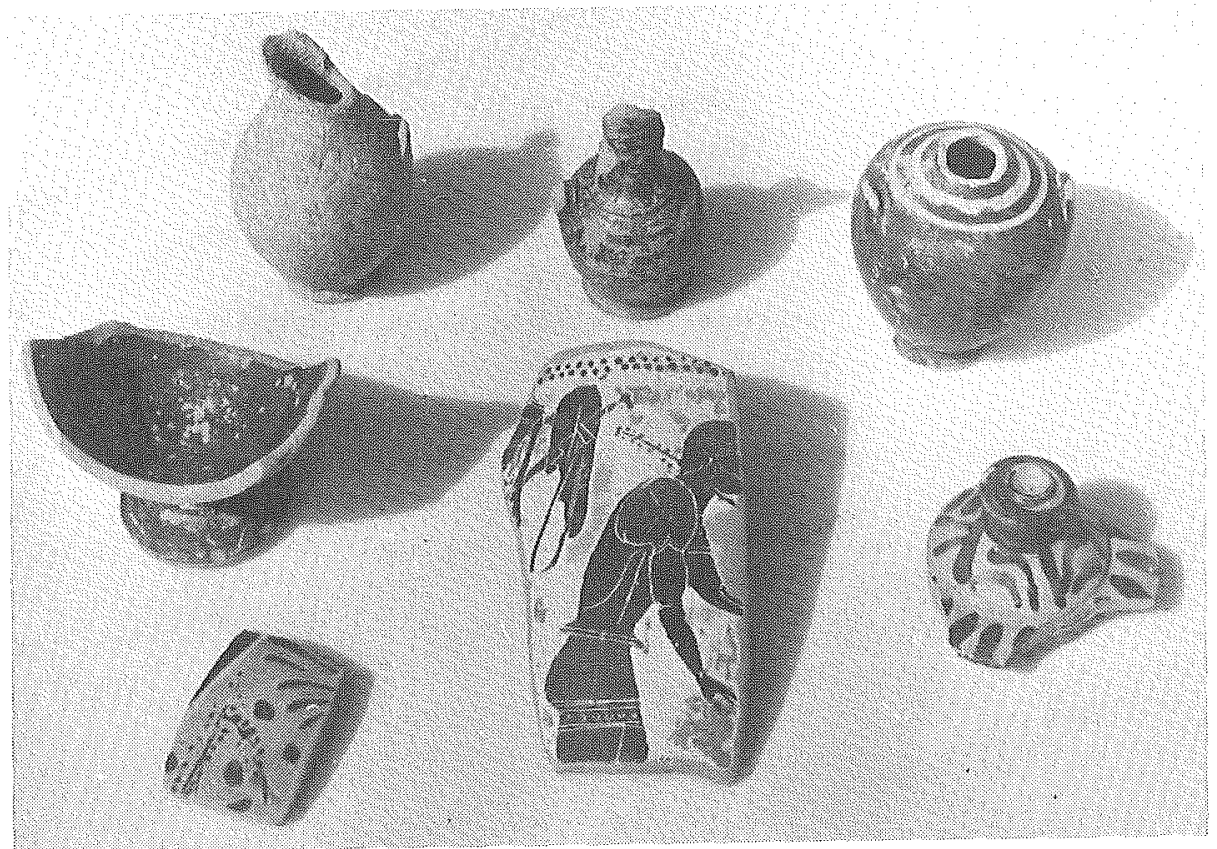

Photo 1

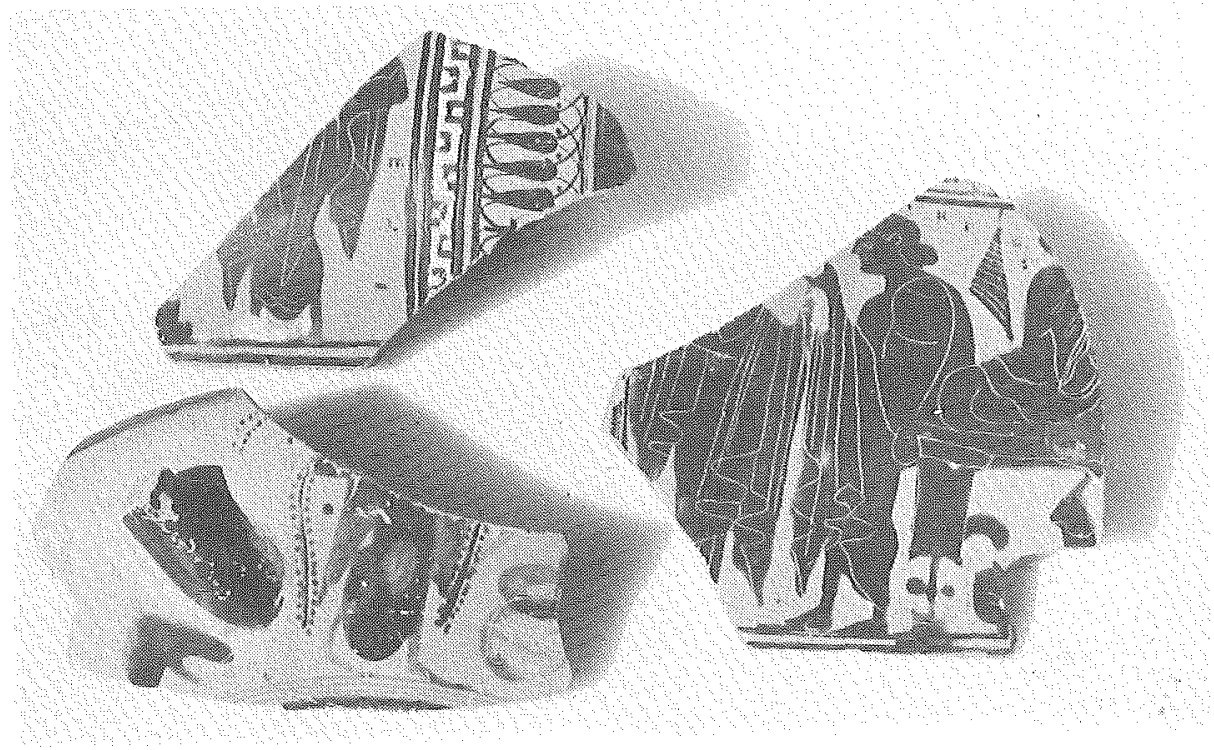

Photo 2 

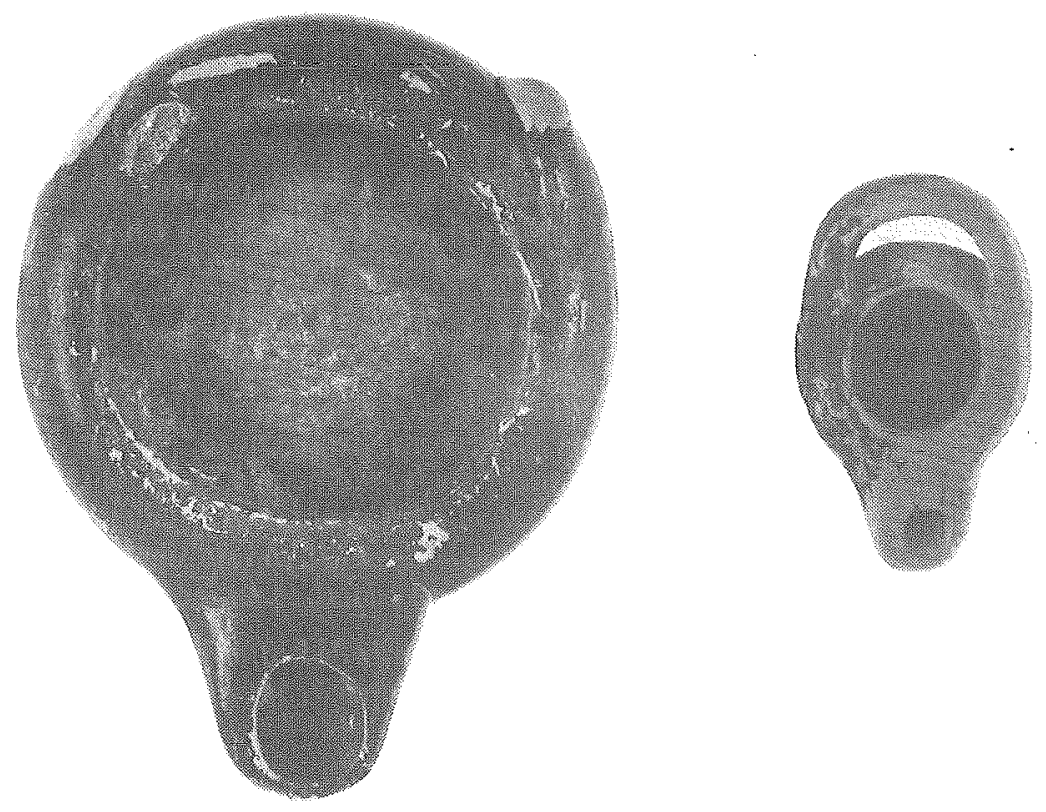

Photo 3

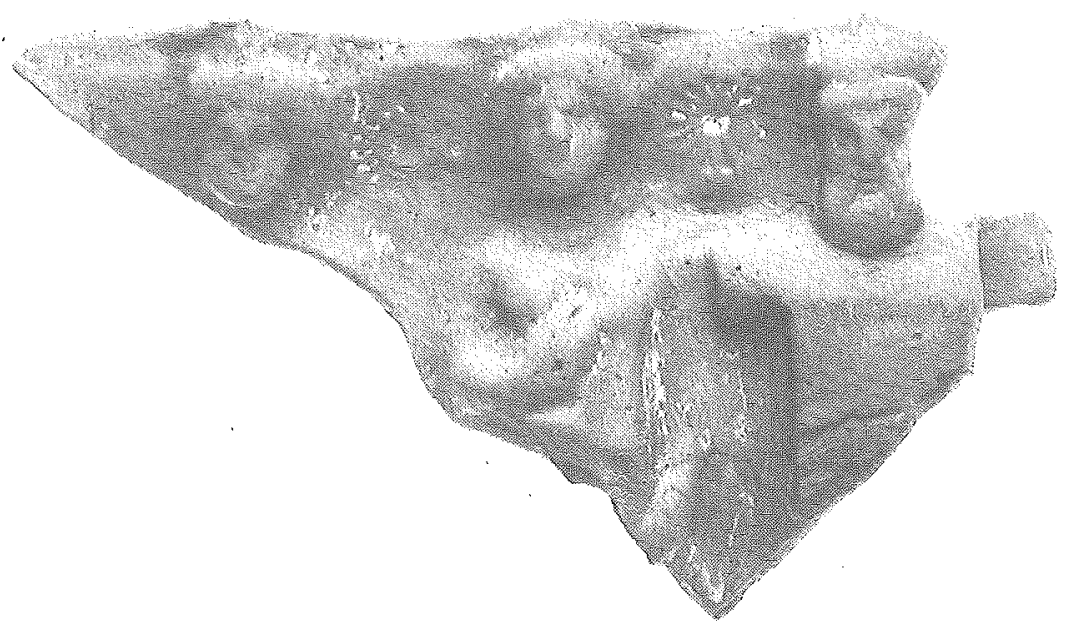

Photo 4 


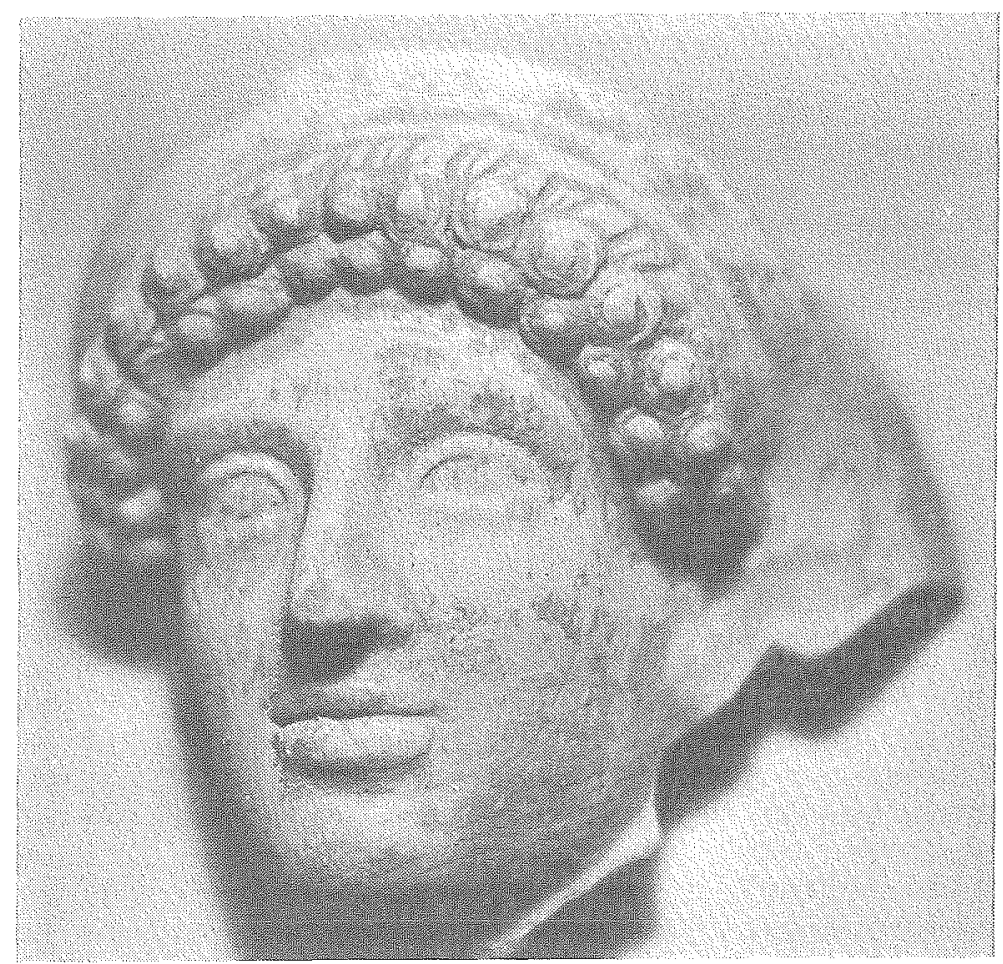

Photos 5

a

b c
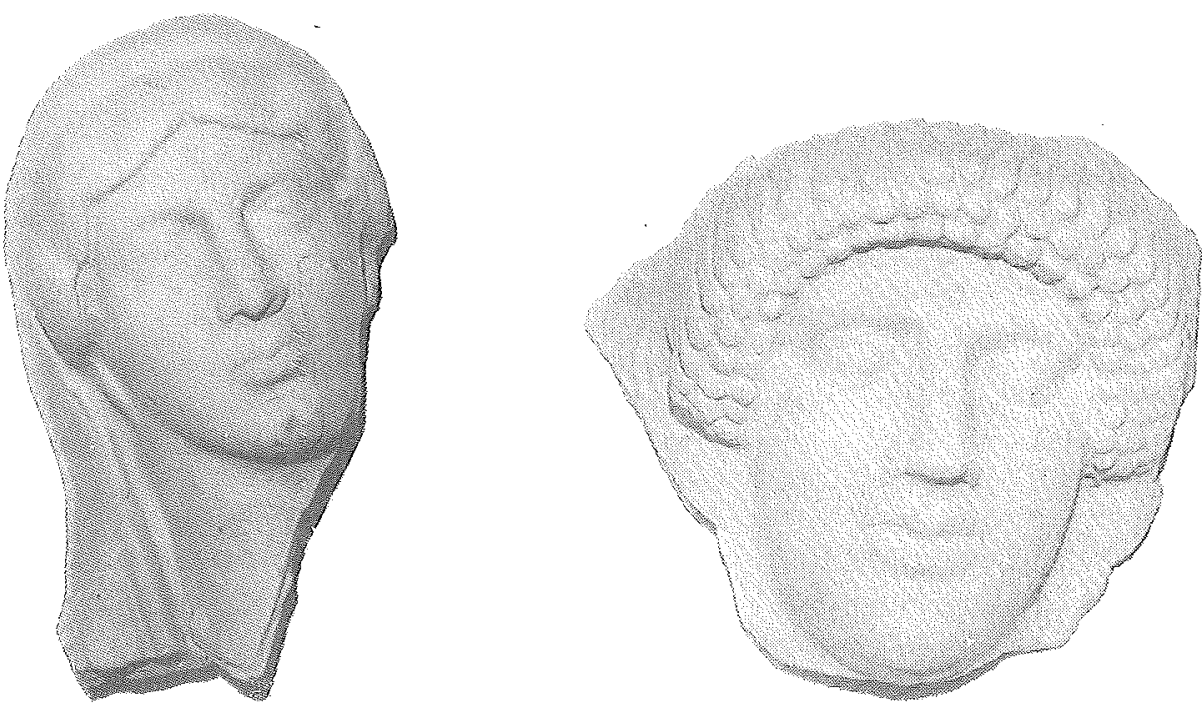

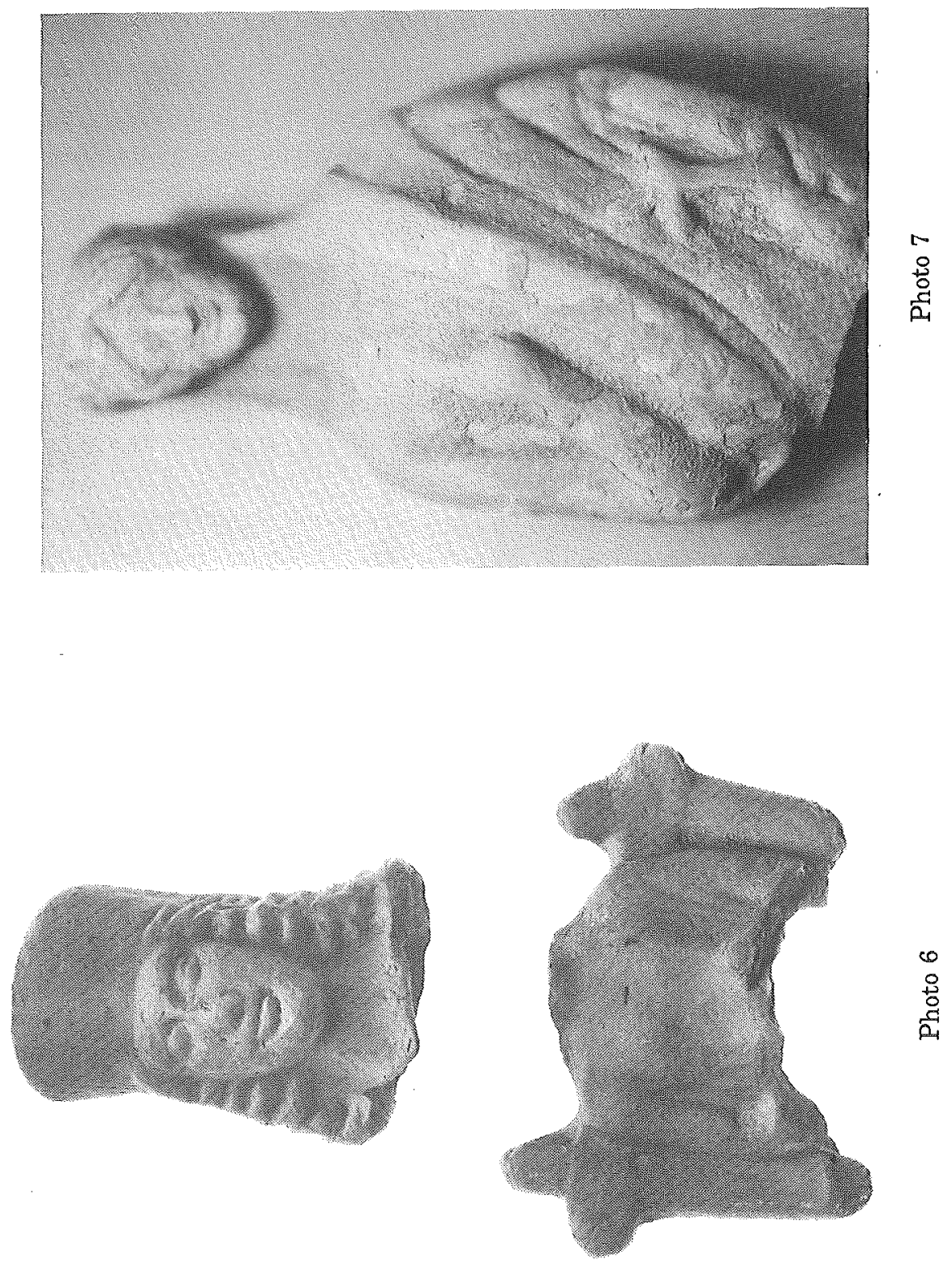


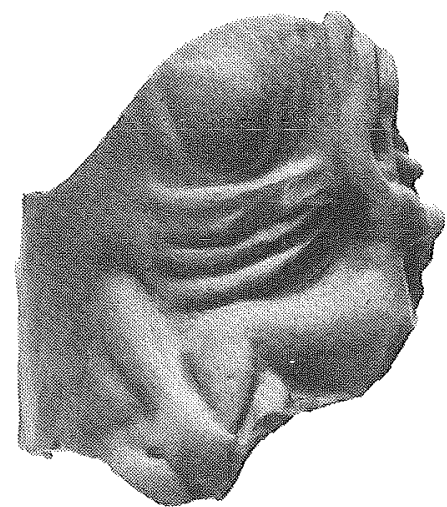

Photo 8

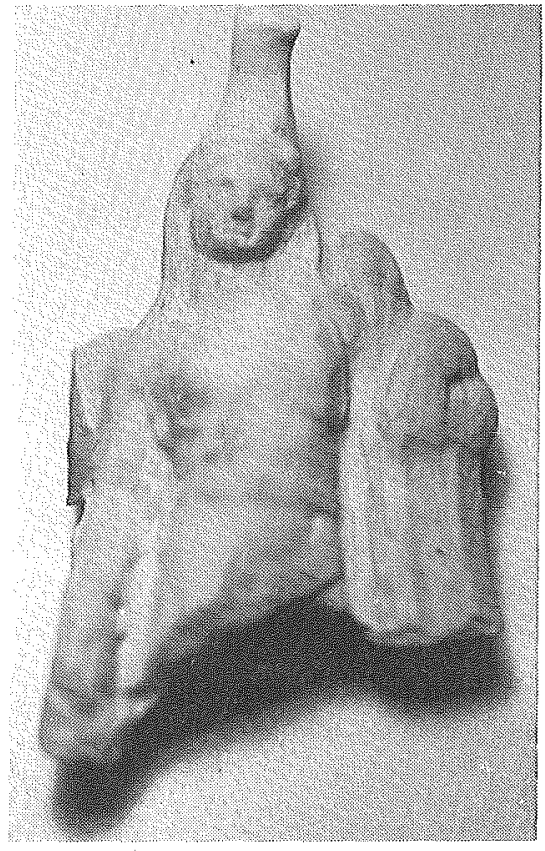

Photo 9a
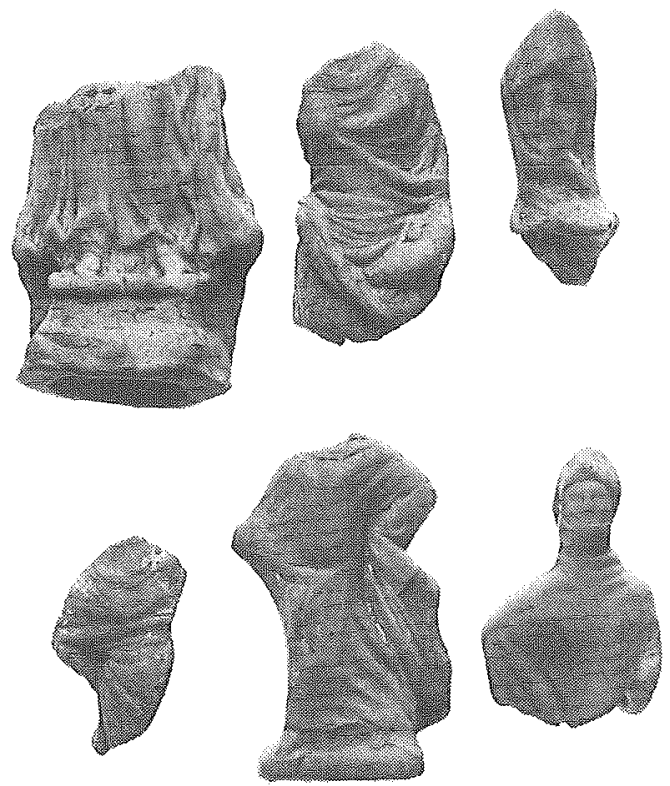

Photo 9b 


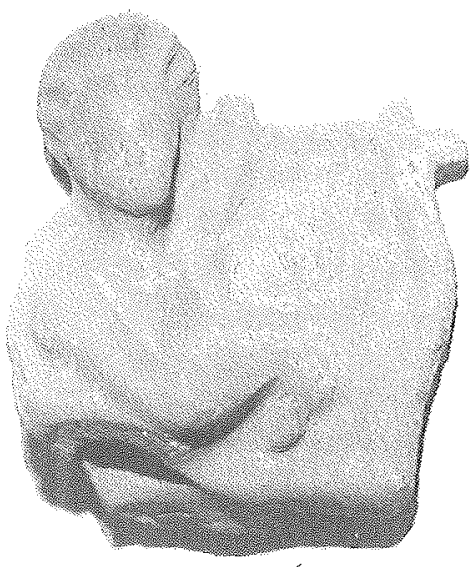

Photo 10
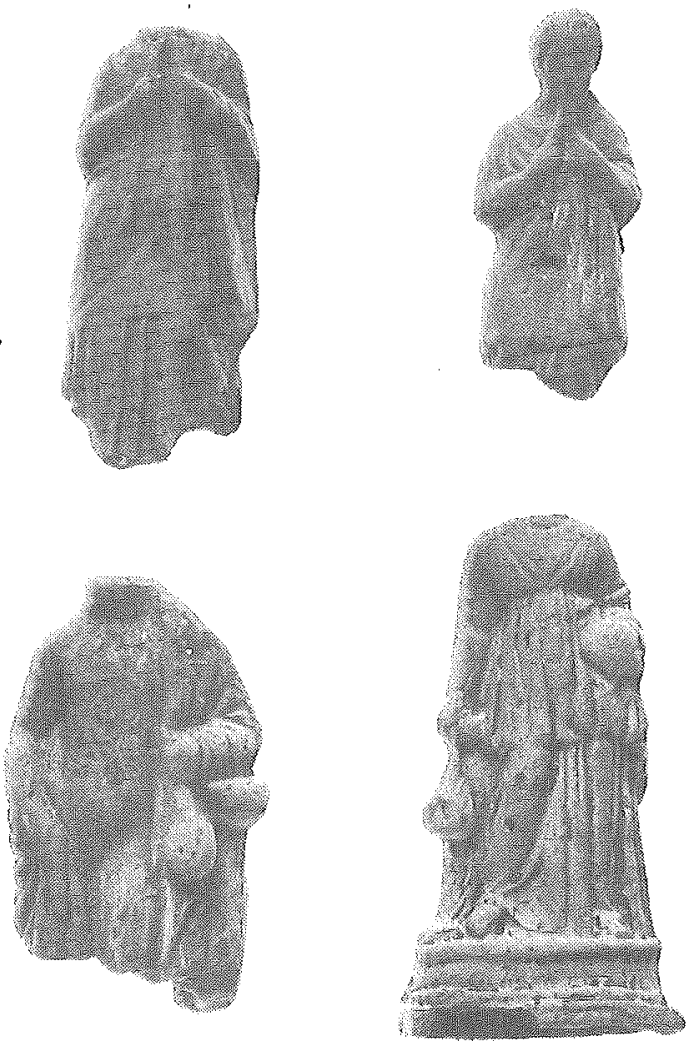

Photo 11 

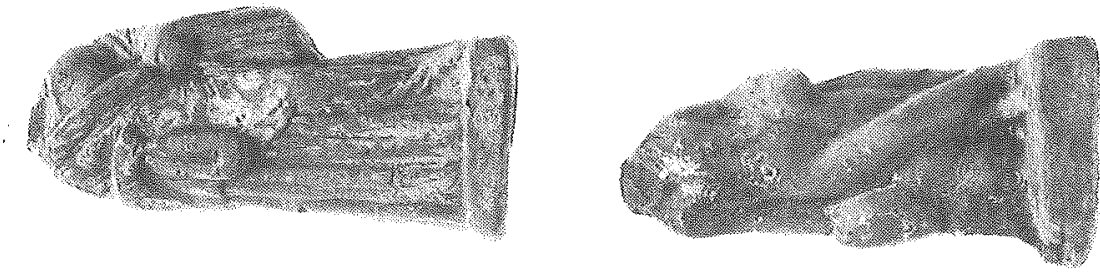

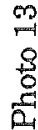
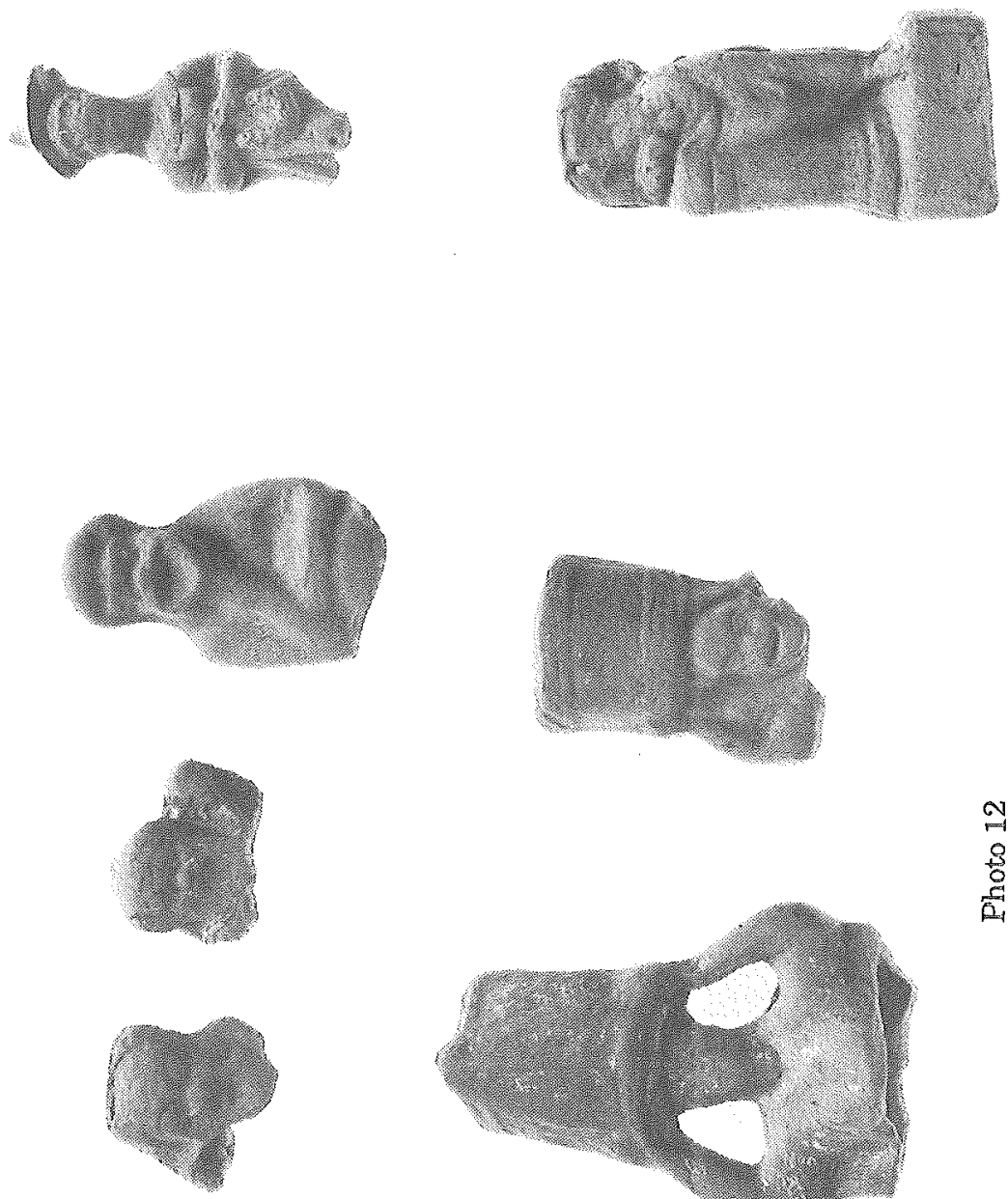

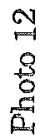

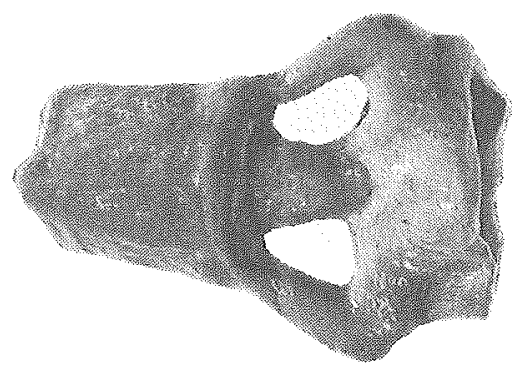



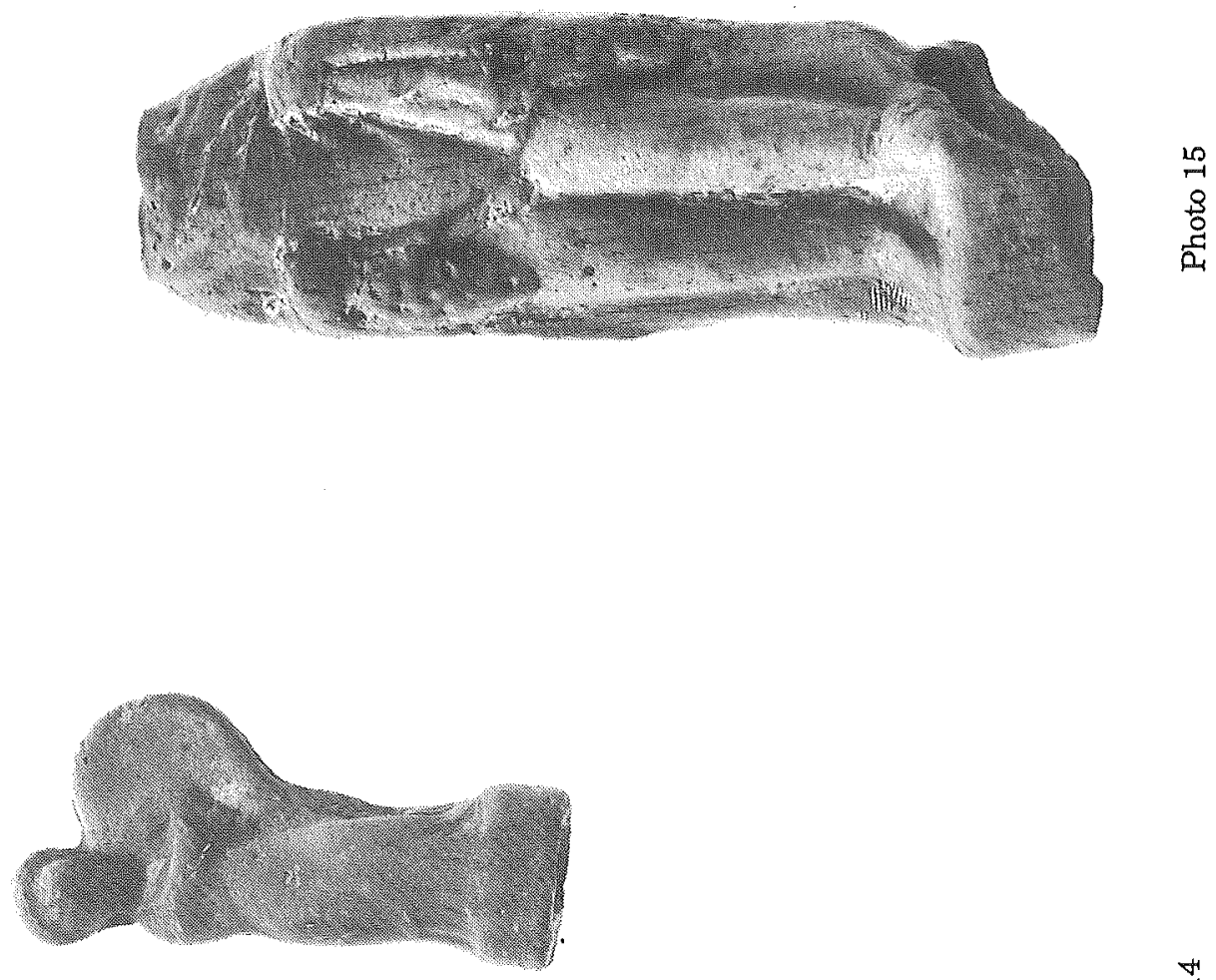

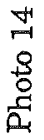
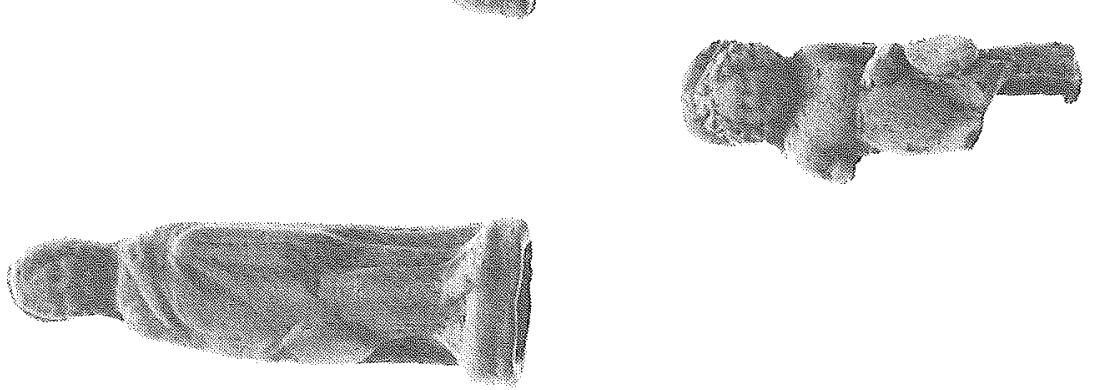

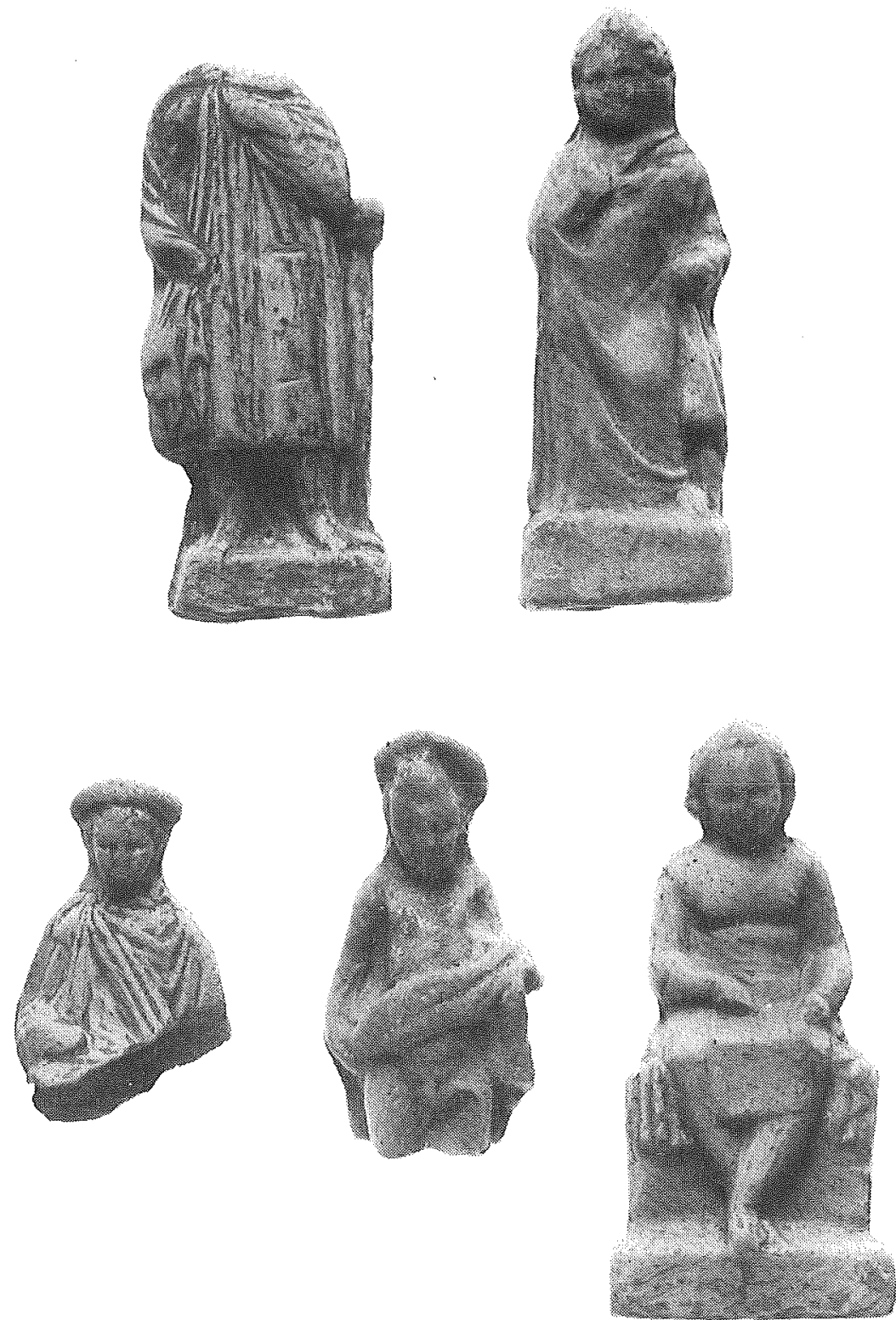

Photo 16 